\title{
Strength of a Corner Zone of a Frame Structure with a Hole to prevent from the fatigue crack
}

\author{
S. Shimizu* \\ Department of Civil Engineering, Shinshu University, \\ Wakasato 4-Chome, Nagano, 380-8553, Japan
}

\begin{abstract}
This paper deals with a thin-walled steel frame structure having shifted beams used as a pier of the motorway viaduct. Some steel box piers of the motorway viaduct are often faced to a serious problem of the crack due to the fatigue at the beam-to-column connection. To prevent from the development of the crack, sometimes, a hole is arranged at the connection of the beam and the column. Such a hole is certainly effective to the crack, however, in this case, the influence to the buckling strength is not considered. Thus, in the current paper, the buckling strength of the column with a hole at the connection of the beam is studied. The elasto-plastic large deflection FEM analysis is made on the column with the plate thickness and the radius of the hole as parameters. The results indicate that the hole shall decrease the strength of the column up to $9 \%$ when the compression stress is arisen near the hole.
\end{abstract}

Keywords: steel box pier, fatigue cracks, hole, buckling strength, beam-to-column connection

\section{Introduction}

This paper represent the numerical results on the influence of a hole, which is arranged to prevent the development of the fatigue cracks, to the buckling strength of a

*Corresponding author. Tel.:+81 262695 313; fax: +81 26269 5271, e-mail: shims00@gipwc.shinshuu.ac.jp 
thin-walled steel frame structure.

Steel rigid frame structures with a box shaped section having shifted beams as illustrated in Fig.1 are sometimes used for the piers of the motorway viaduct.

In the Japanese highway bridge design code (Japanese Specifications for Highway Bridge, JSHB), originally, no fatigue damage was considered in a steel bridge because variation of the load is assumed to be smaller. However, in fact, many serious fatigue cracks are found in the steel bridges, mainly of the trunk expressways or viaducts in the urban areas [1][2].

A fatigue crack itself is a serious damage of the pier. In addition, it may cause the brittle fracture of the pier in case of an earthquake. Therefore, it is important to research on the cause of the fatigue cracks and on measures to prevent its development. In the structures such as shown in Fig.1, cracks due to fatigue are often observed at the beam-to-column connection. Miki, C. et al. indicates that the fatigue cracks are developed by the high stress intensity and the existence of the unwelded zone in the beam-to-column connection [2].

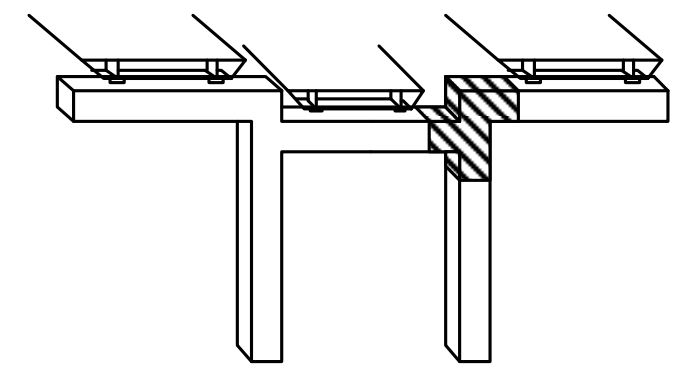

Fig.1. Steel Rigid Frame Structure used as a Pier of the Motorway Viaduct

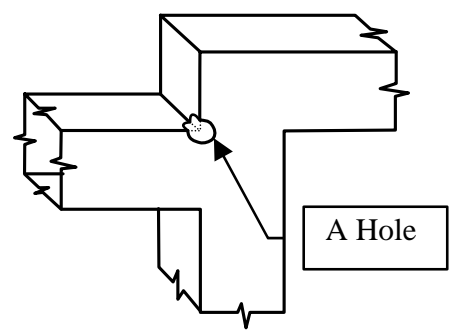

Fig.2. A Hole arranged at the Column-Beam Connection

Recently, in some steel box columns, to remove the unwelded zone and to prevent the development of the crack at the beam-to-column connection, a new idea is proposed by Sasaki et al. that a hole (named as a „Large Core” or „LC”) is arranged at the beam-tocolumn connection as illustrated in Fig.2 [3]. This idea, the Coring Method, is practically applied to the viaduct piers of the Metropolitan Expressway in Tokyo. Such a hole is certainly effective to prevent the development of the fatigue cracks, because the unwelded zone and the zone subjected to the stress intensity near the connection is removed by the core. In [3], Sasaki et al made a study on the effect of the core to the fatigue strength under the seismic load. However, in this study, the influence of the core to the buckling strength is not considered. 
Generally, when a thin walled structure has a hole, the hole may affect the buckling behaviour of the structure. When the hole is the zone subjected to tensile stress, the effect shall be smaller. However, in fact, if the zone with a hole is subjected to the compression, or the alternative stress of compression and tension, the effect of the hole may not be ignored.

With above background, in this paper, a series of numerical analyses is made on the strength of the steel box-sectioned rigid frame used as a pier of a viaduct, having a core at the beam-to-column connection.

\section{Numerical Model}

\section{2-1 General}

In this study, elasto-plastic large deflection Finite Element analysis is made to clarify the influence of the core. The FEM program package MSC-Mark is utilized. The numerical model used in the analysis is assembled with considering an actual steel frame pier which has one beam subtended by two columns and two beams outside of the columns as illustrated in Fig.1, and the column and the beams have $2 \mathrm{~m} \times 2 \mathrm{~m}$ square section. To simplify the problem, in the current analysis, only the hatched part of the frame in Fig.1 is considered. Fig.3 shows the observed part of the frame pier. Considering the layout of the superstructure supported by the original frame structure in Fig.1, this observed part of the frame structure is subjected to the moment and shear shown in Fig.3 (a). In this study, this loading is simplified as illustrated in Fig.3 (b). That is, the flange plates of the beams are subjected to the normal stress $\sigma$ and the web plate is to the shear stress $\tau$, here $\sigma$ and $\tau$ are calculated from $M$ and $P$ with the section area or the moment inertia of the beams, and ratio of normal stress to shear stress is assumed to be $\sigma / \tau=2.0$.

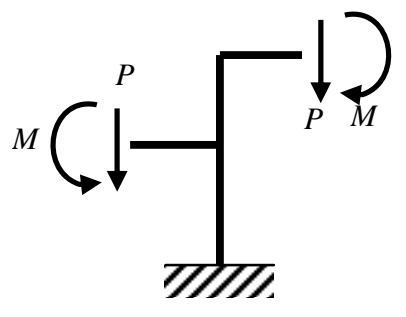

(a) Loadings on the observed part

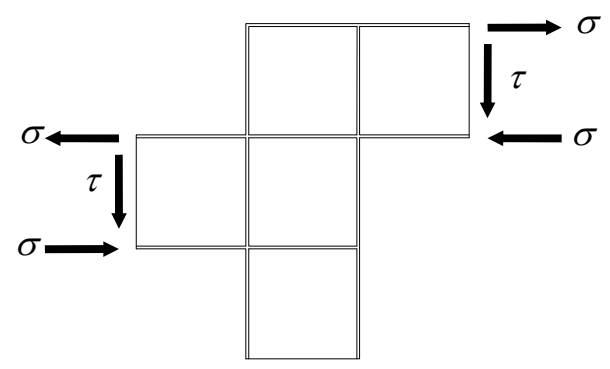

(b) Equivalent stresses

Fig.3. Observed part of Frame with Loadings

It should be noted that the numerical model has two beams and therefore the model is subjected to the shear force $P$ at the each end of the beams. In addition, as described later, the numerical model is considered as only the half part of the practical structure due to its symmetricity. Thus, the practical structure shall be subjected the vertical force of $4 P$ in totally. 
In this study, the strength of the structure is expressed with the value of the shear force $P$.

\section{2-2 Models}

A typical numerical model is illustrated in Fig.4. This is a model shown in Fig.3 with the beam length of $2 \mathrm{~m}$ as shown in Fig.4 (b). Because of its symmetricity, the half part of the column and beams are modelized, and the each end of the beams are covered by a virtual stiff diaphragms to hold the appropriate stiffness of the system as shown in Fig.4 (a). Plate thickness $t$ in Fig.4 (b) is considered as one of the parameters as described later. The black points in Fig.4(a) and (b) indicate that the vertical displacement of this point is discussed in the load-deflection relation in 3-2.

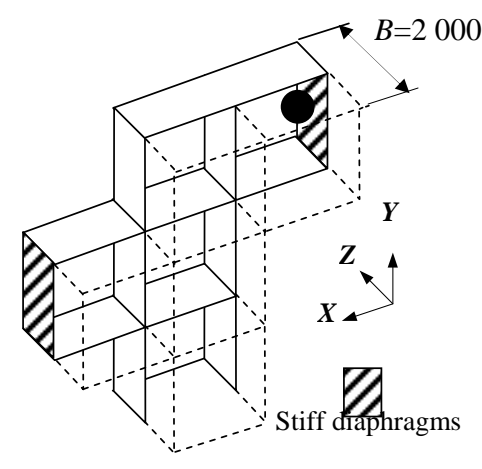

(a) Model Layout

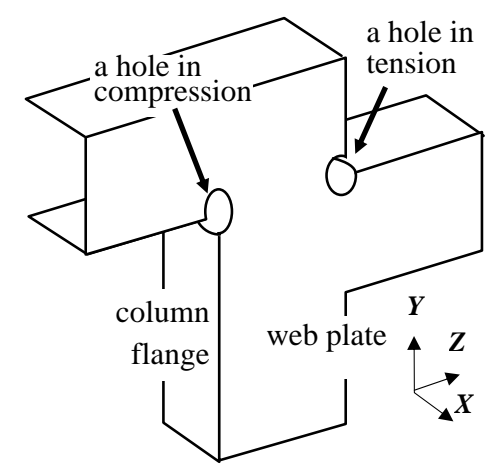

(a) Hole Arrangement

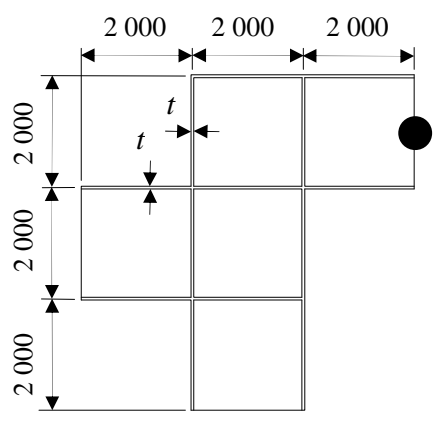

(b) Model Dimensions

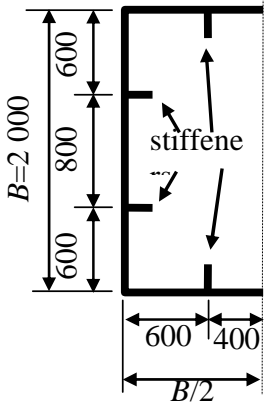

(c) stiffener layout

Fig.4. Numerical Model
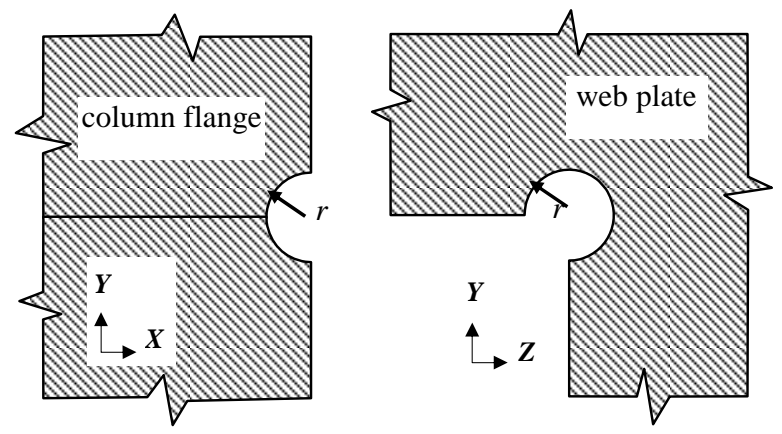

(b) Hole Layout

Fig.5. Detail of Holes

In some cases, stiffeners with the section dimensions of 200 x $20 \mathrm{~mm}$ are considered in the column and the beams as shown in Fig.4 (c). Fig.4 (c) shows the section of the beams or the column, and two stiffeners are arranged in one face of the beams or the column. 
Fig.5 shows the detail of the LC (large core, holes arranged at the beam-to-column connection) layout. It should be noted that the numerical model in Fig. $\mathbf{5}$ is illustrated in the opposite direction of those in the previous figures. In this study, a core is assumed to be arranged in the compression corner or the tension corner of the connection in Fig.5 (a). The shapes and the dimension of a core are indicated in Fig.5 (b), i.e. a core has the radius $r$ both in the Y-Z plane (in the web plate) and in the $X-Z$ plane (in the flange plate of the column), here the radius $r$ is also one of the parameter.

\section{2-3 Core radius, plate thickness and material properties}

The core radius $r$ of the current study is varied as $r=50-100 \mathrm{~mm}$. This value is decided from the practical core dimension arranged in the metropolitan expressway in Tokyo. In addition, the model with no core is analyzed for the comparison purpose. In this paper, core radius $r=0$ means that the model has no core.

Thickness of plate is varied $t=10,12,15,18,20$ or $30 \mathrm{~mm}$ for models with stiffeners and 20 or $50 \mathrm{~mm}$ for models without stiffeners.

Table 1. Plate thickness with undimensioned width-thickness ratio $R$

\begin{tabular}{ccccccccc}
\hline & \multicolumn{9}{c}{ with stiffeners } & \multicolumn{2}{c}{ without stiffeners } \\
\hline$t(\mathrm{~mm})$ & 10 & 12 & 15 & 18 & 20 & 30 & 20 & 50 \\
\hline$R$ & 1.70 & 1.41 & 1.13 & 0.92 & 0.84 & 0.45 & 2.09 & 0.81 \\
\hline
\end{tabular}

In Table 1, plate thickness $t$ used in the analysis is summarized. In this table, undimensioned width-thickness ratio $R$ calculated with the equation

$$
R=\frac{b}{t} \sqrt{\frac{\sigma_{y}}{E} \cdot \frac{12 \cdot\left(1-v^{2}\right)}{k \cdot \pi^{2}}}
$$

is also shown, where when the plate has $R$ less than $1.0(R<1.0)$, yielding shall be initiated earlier than buckling of the plate, and when $\mathrm{R}>1.0$ buckling shall arisen earlier. $\sigma_{\mathrm{y}}, E, v$ in the equation (1) denote yield stress, Young's modulus and Poisson's ratio of the material respectively, $k$ the buckling coefficient of the plate, and $b$ denotes the panel width (equal to $B$ when the model has no stiffener, and spacing of stiffeners $800 \mathrm{~mm}$ for the model with stiffeners). In the current study, $E=200 \mathrm{GPa}$ and $v=0.3$ are adopted and the buckling coefficient $k$ is assumed to be $k=4.0$. The yield stress is $\sigma_{\mathrm{y}}=325 \mathrm{MPa}$ for $t=10,12$ or $15 \mathrm{~mm}, \sigma_{\mathrm{y}}=315 \mathrm{MPa}$ for $t=18,20$ or $30 \mathrm{~mm}$ and $\sigma_{\mathrm{y}}=295$ MPa for $t=50 \mathrm{~mm}$, which are corresponding to those of the grade SM490 steel.

The virtually stiff diaphragms arranged at the both edges of the beams are assumed to have Young's modulus of $E=2.00 \times 10^{8} \mathrm{GPa}$.

\section{2-4 FEM mesh discretization}

Fig. 5 is showing an example of the FEM mesh pattern used in the current analysis. In this figure, the mesh pattern of the model with stiffeners and the core of radius $r=50$ $\mathrm{mm}$ in tension is shown. For the analysis, the rectangular and triangle thin shell 
elements are used. As it is found from the figure, finer mesh pattern is used near the core. The bottom part of the model is considered to be fixed, and the appropriate boundary conditions are applied to satisfy the symmetricity of the model.

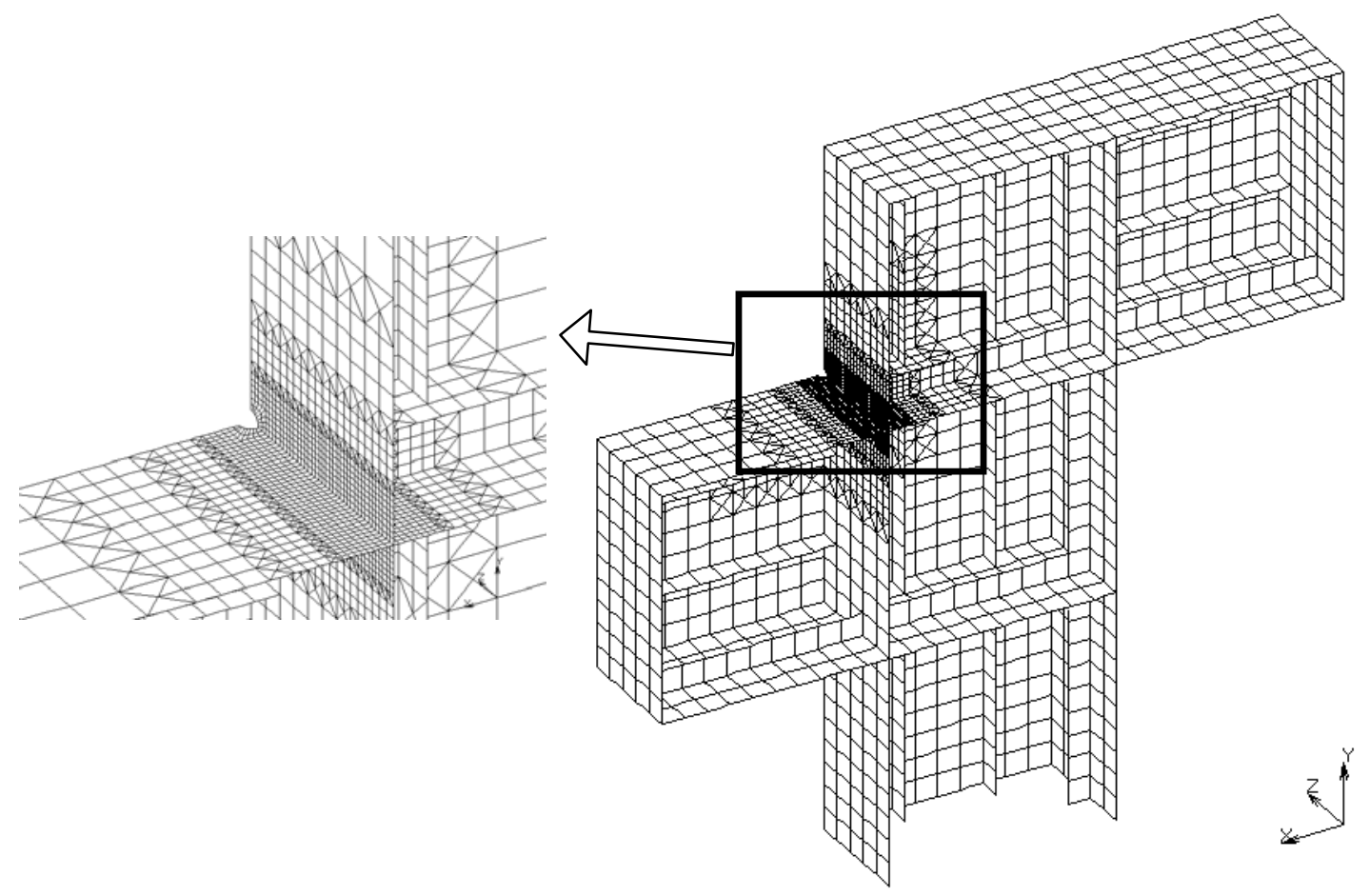

Fig.6. An example of FEM Mesh discretization

\section{Numerical Results}

\section{3-1 Maximum load}

Table 2 shows the maximum load $(\mathrm{kN})$ of each model obtained through the current analysis. The maximum load in this table refers the load $P$ described in 2-1 and Fig.3 of this paper. In this table, $t$ denotes the plate thickness of the models in $\mathrm{mm}$, and $r$ the radius of the core in $\mathrm{mm}$, here $r=0$ means that no core is arranged on the model. The figures in the parentheses are ratios of the maximum load for the case with no core.

When a core is arranged in the tension zone, this table indicates that the core has small contribution for the strength. In the Table 2 (a), the model having no stiffener with $r=100 \mathrm{~mm}$ has the maximum load of $1-2 \%$ smaller than the model with no core, and the model having stiffeners, a core with $r=100 \mathrm{~mm}$ make the maximum load of 1 3\% smaller in Table 2(c).

On the other hand, this table indicates that the core arranged in the compression zone shall affect the maximum load. In Table 2(b) with no stiffener, the model of $t=20 \mathrm{~mm}$, the plate thickness by which buckling is initiated earlier, has the maximum load of $7 \%$ than one of $r=0$, and the model of $t=30 \mathrm{~mm}$ has the maximum load of $5 \%$ smaller than one of $r=0$. On the case that the models have stiffeners shown in Table 
2(d), the model with $t=10 \mathrm{~mm}$ has the maximum load $8 \%$ smaller than the model with no core when the core radius $r=100 \mathrm{~mm}$, and the model of $t=12$ has $11 \%$ smaller. In the case in Table 2(d), the models with thicker plate have the maximum of 5-4\% smaller.

Table 2. Maximum Load (kN)

(a) core in tension side, No stiffener

\begin{tabular}{cccccccc}
\hline & $r=0$ & $r=50$ & $r=60$ & $r=70$ & $r=80$ & $r=90$ & $r=100$ \\
\hline \multirow{2}{*}{$t=20$} & 4710 & 4670 & 4659 & 4653 & 4646 & 4638 & 4630 \\
& $(100 \%)$ & $(99 \%)$ & $(99 \%)$ & $(99 \%)$ & $(99 \%)$ & $(98 \%)$ & $(98 \%)$ \\
\hline \multirow{2}{*}{$t=50$} & 15677 & 15601 & 15581 & 15560 & 15540 & 15520 & 15500 \\
& $(100 \%)$ & $(100 \%)$ & $(99 \%)$ & $(99 \%)$ & $(99 \%)$ & $(99 \%)$ & $(99 \%)$ \\
\hline
\end{tabular}

(b) core in compression side, No stiffener

\begin{tabular}{lccccccc}
\hline & $r=0$ & $r=50$ & $r=60$ & $r=70$ & $r=80$ & $r=90$ & $r=100$ \\
\hline \multirow{2}{*}{$t=20$} & 4713 & 4642 & 4607 & 4559 & 4506 & 4439 & 4360 \\
& $(100 \%)$ & $(98 \%)$ & $(98 \%)$ & $(97 \%)$ & $(96 \%)$ & $(94 \%)$ & $(93 \%)$ \\
\hline \multirow{2}{*}{$t=50$} & 15707 & 15393 & 15304 & 15212 & 15123 & 15031 & 14939 \\
& $(100 \%)$ & $(98 \%)$ & $(97 \%)$ & $(97 \%)$ & $(96 \%)$ & $(96 \%)$ & $(95 \%)$ \\
\hline
\end{tabular}

(c) core in tension side, with stiffener of 200x20 mm

\begin{tabular}{cccccccc}
\hline & $r=0$ & $r=50$ & $r=60$ & $r=70$ & $r=80$ & $r=90$ & $r=100$ \\
\hline \multirow{2}{*}{$t=10$} & 3023 & 2989 & 2981 & 2973 & 2964 & 2956 & 2947 \\
& $(100 \%)$ & $(99 \%)$ & $(99 \%)$ & $(98 \%)$ & $(98 \%)$ & $(98 \%)$ & $(97 \%)$ \\
\hline \multirow{2}{*}{$t=12$} & 3857 & 3829 & 3823 & 3816 & 3807 & 3798 & 3785 \\
& $(100 \%)$ & $(99 \%)$ & $(99 \%)$ & $(99 \%)$ & $(99 \%)$ & $(98 \%)$ & $(98 \%)$ \\
\hline \multirow{2}{*}{$t=15$} & 5104 & 5068 & 5058 & 5048 & 5036 & 5027 & 5018 \\
& $(100 \%)$ & $(99 \%)$ & $(99 \%)$ & $(99 \%)$ & $(99 \%)$ & $(98 \%)$ & $(98 \%)$ \\
\multirow{2}{*}{$t=18$} & 6069 & 6025 & 6015 & 6005 & 5995 & 5984 & 5974 \\
& $(100 \%)$ & $(99 \%)$ & $(99 \%)$ & $(99 \%)$ & $(99 \%)$ & $(99 \%)$ & $(99 \%)$ \\
\multirow{2}{*}{$t=20$} & 6803 & 6761 & 6752 & 6742 & 6732 & 6721 & 6711 \\
& $(100 \%)$ & $(99 \%)$ & $(99 \%)$ & $(99 \%)$ & $(99 \%)$ & $(99 \%)$ & $(99 \%)$ \\
\hline \multirow{2}{*}{$t=30$} & 10837 & 10781 & 10766 & 10750 & 10734 & 10717 & 10700 \\
& $(100 \%)$ & $(99 \%)$ & $(99 \%)$ & $(99 \%)$ & $(99 \%)$ & $(99 \%)$ & $(99 \%)$ \\
\hline
\end{tabular}

(d) core in compression side, with stiffener of 200x20 mm

\begin{tabular}{cccccccc}
\hline & $r=0$ & $r=50$ & $r=60$ & $r=70$ & $r=80$ & $r=90$ & $r=100$ \\
\hline \multirow{2}{*}{$t=10$} & 2954 & 2843 & 2801 & 2768 & 2748 & 2726 & 2710 \\
& $(100 \%)$ & $(96 \%)$ & $(95 \%)$ & $(94 \%)$ & $(93 \%)$ & $(92 \%)$ & $(92 \%)$ \\
\hline \multirow{2}{*}{$t=12$} & 3825 & 3694 & 3647 & 3521 & 3463 & 3436 & 3413 \\
& $(100 \%)$ & $(97 \%)$ & $(95 \%)$ & $(92 \%)$ & $(91 \%)$ & $(90 \%)$ & $(89 \%)$ \\
\hline \multirow{2}{*}{$t=15$} & 5072 & 4988 & 4974 & 4964 & 4923 & 4838 & 4830 \\
& $(100 \%)$ & $(98 \%)$ & $(98 \%)$ & $(98 \%)$ & $(97 \%)$ & $(95 \%)$ & $(95 \%)$ \\
\hline \multirow{2}{*}{$t=18$} & 6058 & 5946 & 5919 & 5890 & 5858 & 5828 & 5801 \\
& $(100 \%)$ & $(98 \%)$ & $(98 \%)$ & $(97 \%)$ & $(97 \%)$ & $(96 \%)$ & $(96 \%)$ \\
\multirow{2}{*}{$t=20$} & 6783 & 6670 & 6636 & 6601 & 6564 & 6528 & 6496 \\
& $(100 \%)$ & $(98 \%)$ & $(98 \%)$ & $(97 \%)$ & $(97 \%)$ & $(96 \%)$ & $(96 \%)$ \\
\hline \multirow{2}{*}{$t=30$} & 10901 & 10775 & 10716 & 10641 & 10545 & 10428 & 10316 \\
& $(100 \%)$ & $(99 \%)$ & $(98 \%)$ & $(98 \%)$ & $(97 \%)$ & $(96 \%)$ & $(95 \%)$ \\
\hline
\end{tabular}


Thus, the results in Table 2 suggest that attention must be paid on the decrease of strength when a core is arranged in the compression zone or a zone subjected to the alternative stress of tension and compression. The table also suggests that, when a model has thinner plate which leads buckling rather than yielding, the model has much smaller strength than the model with thicker plate.

\section{3-2 P- $\delta$ Relations}

The load-deflection relations of the principal models are plotted in Fig.7. The models in this figure have cores arranged in the compression side. In this figure, the deflection $\delta$ is referring to the vertical displacement at the edge of the upper beam (shown as black points in Fig.4 (a) or (b) ).

On the models in Fig.7(a), the load-deflection relations have almost same path until the load is reached to $3500 \mathrm{kN}$, and beyond this load, the deflection begins to increased a little faster rate. The $P-\delta$ relations in this figure show that the load is decreased in the faster rate after the peak is reached than the other cases.

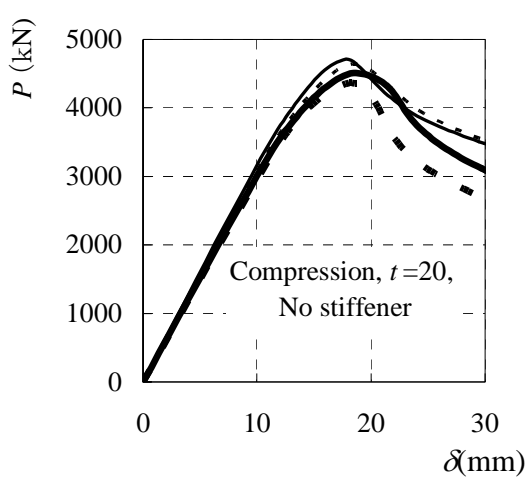

(a) Without Stiffener, $t=20 \mathrm{~mm}$

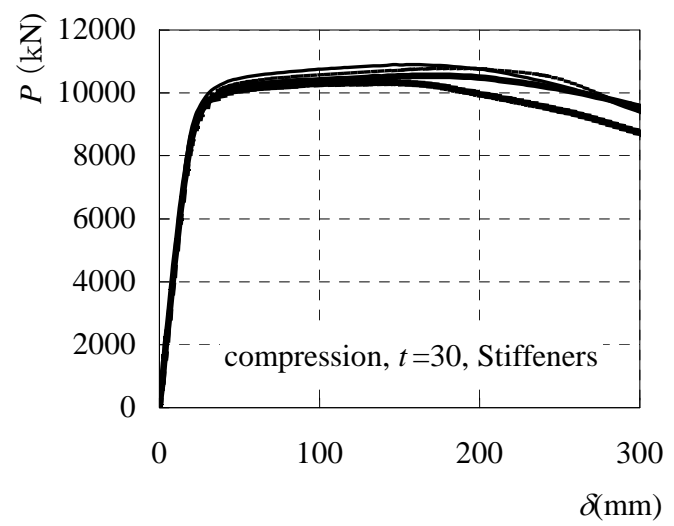

(c) With Stiffeners, $t=30 \mathrm{~mm}$

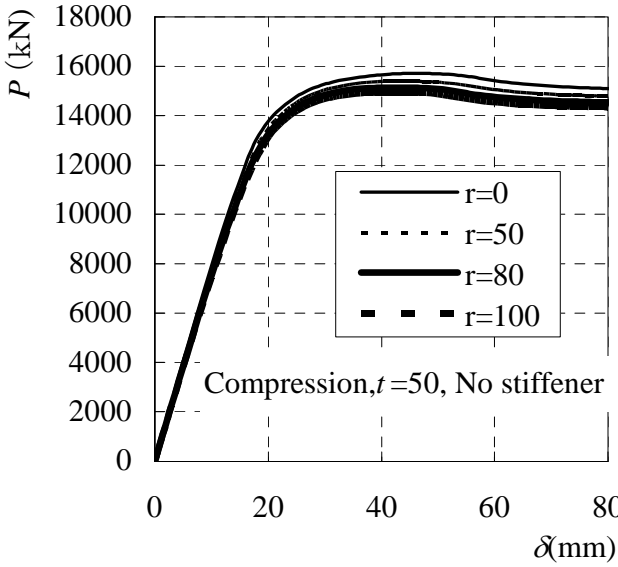

(b) Without Stiffener, $t=50 \mathrm{~mm}$

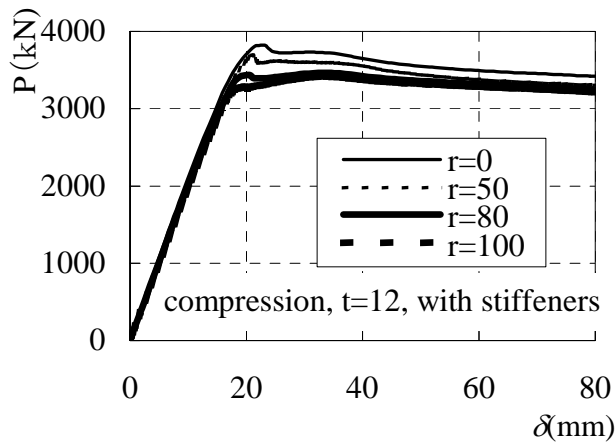

(d) With Stiffeners, $t=12 \mathrm{~mm}$

Fig.7 P-d relations of models with a core in the compression side 
In Fig.7.(b), the slope of the curves begins to be reduced gradually after the load is $14000 \mathrm{kN}$, and it reaches to the peak load smoothly. After the peak, the load is decreased gradually. This is almost similar to the models in Fig.7(c), although the deflection in Fig.7(c) increases in faster rate after the load of $10000 \mathrm{kN}$. In these two cases in Figs.7. (b) and (c), influence of the core radius seems to be smaller than the modes in Fig.7(a).

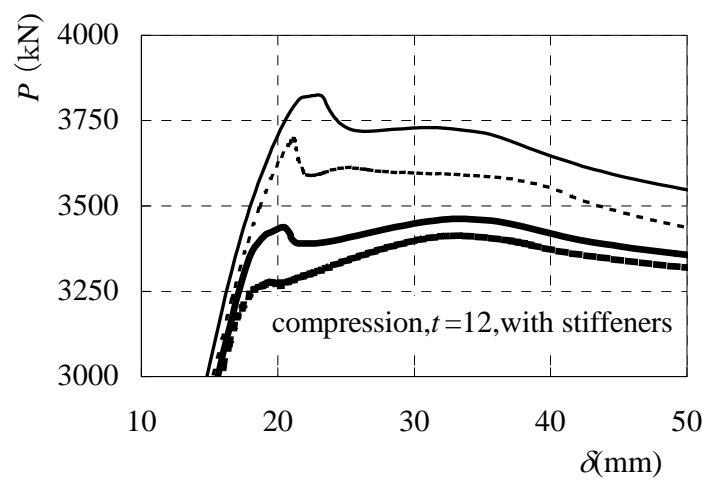

(a) core in conmpression

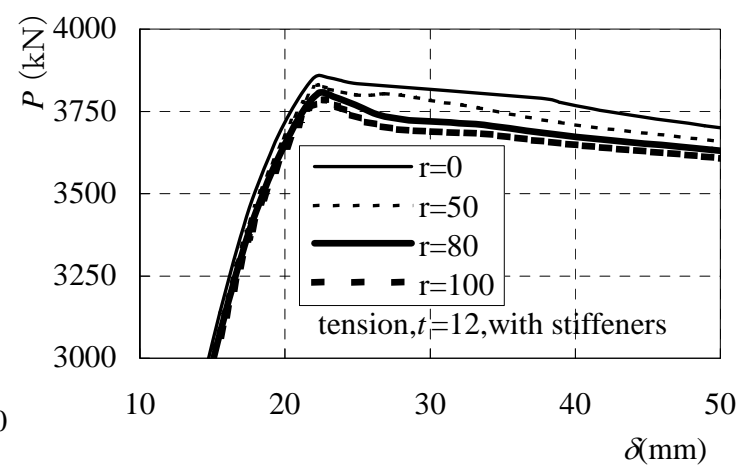

(b) core in tension

Fig.8. Enlarged $P$ - $\delta$ relations of models with stiffeners and $t=12$, Hole in Compression

The models in Fig.7.(d), which are with $t=12 \mathrm{~mm}$ and stiffeners are aranged, have a little diferent load-deflection behaviour from other cases near the peak loads. Fig.8(a) shows the enlarged load-deflection relations near the peaks of the models in Fig.7(d). In this figure, for the comparison purpose, $P$ - $\delta$ relations of the same case with the core in the tension side are shown in Fig.8(b). These models have curves almost linear in the earlier stage, however, Fig.7(d) or Fig.8(a) indicate that the $P$ - $\delta$ relation in these models have a kind of transition from the initial lines to the other path.

When the load is reached to $P=3201 \mathrm{kN}$, the curve of $r=100 \mathrm{~mm}$ begins to incline, and the deflection is increased up to $\delta=21 \mathrm{~mm}$ without increasing of load. After this

stage, the load is increased slightly in this model, and the peak load of $3413 \mathrm{kN}$ is reached at $\delta=33 \mathrm{~mm}$.

The model with $r=80 \mathrm{~mm}$ has the curve whose deflection begins to increase with a little faster rate after $P=3359 \mathrm{kN}$, then the load is reached to $3437 \mathrm{kN}$. After this stage, the load of this model is once decreased to $P=3413 \mathrm{kN}$, then the load is increased slightly and the peak load of $3463 \mathrm{kN}$ is reached at $\delta=33 \mathrm{~mm}$.

On the model of $r=50$, the slope of the curve changes slightly after the load of about $3500 \mathrm{kN}$, and at $\delta=21 \mathrm{~mm}$ peak load of $3694 \mathrm{kN}$ is reached. After the peak, the load of this model decreases rapidly up to $3588 \mathrm{kN}$, then the load is increased slightly to increased to $P=3611 \mathrm{kN}$ with $\delta=26 \mathrm{~mm}$, then the load begins to decrease.

The slope of the curve of the model with no core $(r=0)$ also changed slightly at the load of about $3500 \mathrm{kN}$, then the maximum load of $3825 \mathrm{kN}$ is reached with $\delta=23 \mathrm{~mm}$. After this stage, the load of this model is decreased to $3718 \mathrm{kN}$ at $\delta=27 \mathrm{~mm}$, then the deflection is increased up to $\delta=31 \mathrm{~mm}$ with very small increase of the load. 
As described, models in Fig.7 has a core in the compression side. When a core is arranged in the tension side, the models have almost similar $P$ - $\delta$ relations except the case with $t=12 \mathrm{~mm}$ and having stiffeners, although the difference caused by the radius of the core is smaller when the core is in the tension side. That is, the slope of the curves becomes smaller gradually, then the peak is reached smoothly.

On the case with $t=12 \mathrm{~mm}$ and having stiffeners, the slope of the $P$ - $\delta$ curves changed at the load of $3500 \mathrm{kN}$ slightly. However, beyond this load level, the load is increased still almost linearly, and the peak load is reached suddenly. After the peak, the load is reduced gradually in this model.
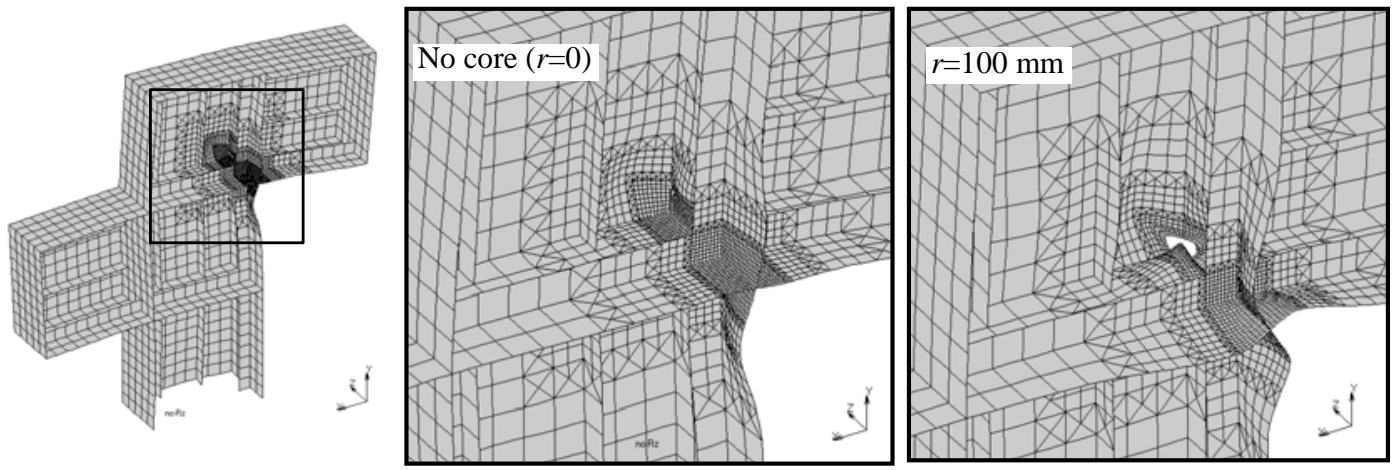

Fig.9 Deformation patterns of the models with $\mathrm{t}=12 \mathrm{~mm}$ having stiffeners, Core in compression

Fig.9 shows the deformation pattern of the models with $t=12 \mathrm{~mm}$. In this figure, the deformation is enlarged by 5 times. Both models have deformation on the panel subtended by stiffeners in the flange plate of the column just below the connection. In addition, on the model with $r=100$, deformation is also observed in the beam flange and the plate panel adjacent the core. As it is found from the figure, on the model with no core, the deformation for the inward direction is observed. Although the figure is not shown in this paper, the model with $r=50$ also has the inward deformation. On the other hand, the model of $r=100$ has outward deformation. This is also true for the case of $r=80$.

On these models, such deformation is arisen almost suddenly at the stage of the transition of the load-deflection relation from the initial line. This fact suggests that the buckling of the column flange causes the transition of the $P-\delta$ relation.

The other models have also the deformation in the column flange although the figure is notshown. However, in the other models, deformation is developed gradually with the increasing load, and the significant deformation is not found in the beam flange even the core radius $r=100$.

\section{3-2 Stress Distributions}

In Fig.10, the stress distribution patterns of the beam flange measured along the beam-to-column connection are plotted at the load level of $P=84 \mathrm{kN}$ (first step of the analysis), for the model with plate thickness $t=20 \mathrm{~mm}$ and with no stiffener. In this 
figures, stresses along the thick black lines with $d=50 \mathrm{~mm}$ and $d=200 \mathrm{~mm}$ illustrated in Fig.11 are used, here $d$ denotes the distance from the connection.

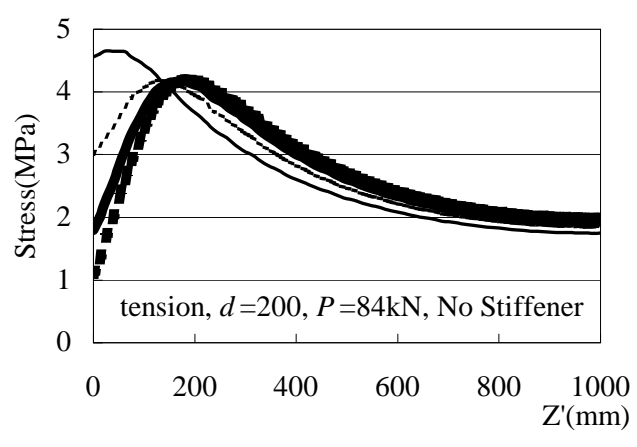

(a) stress at $d=200 \mathrm{~mm}$

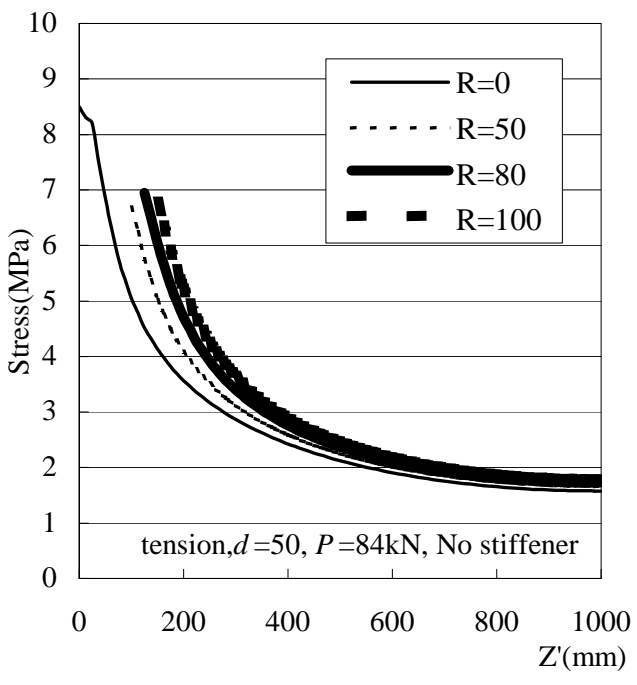

(b) stress at $d=50 \mathrm{~mm}$

Fig.10. Stress along the beam-to-column connection, in elastic range (hole in tension)
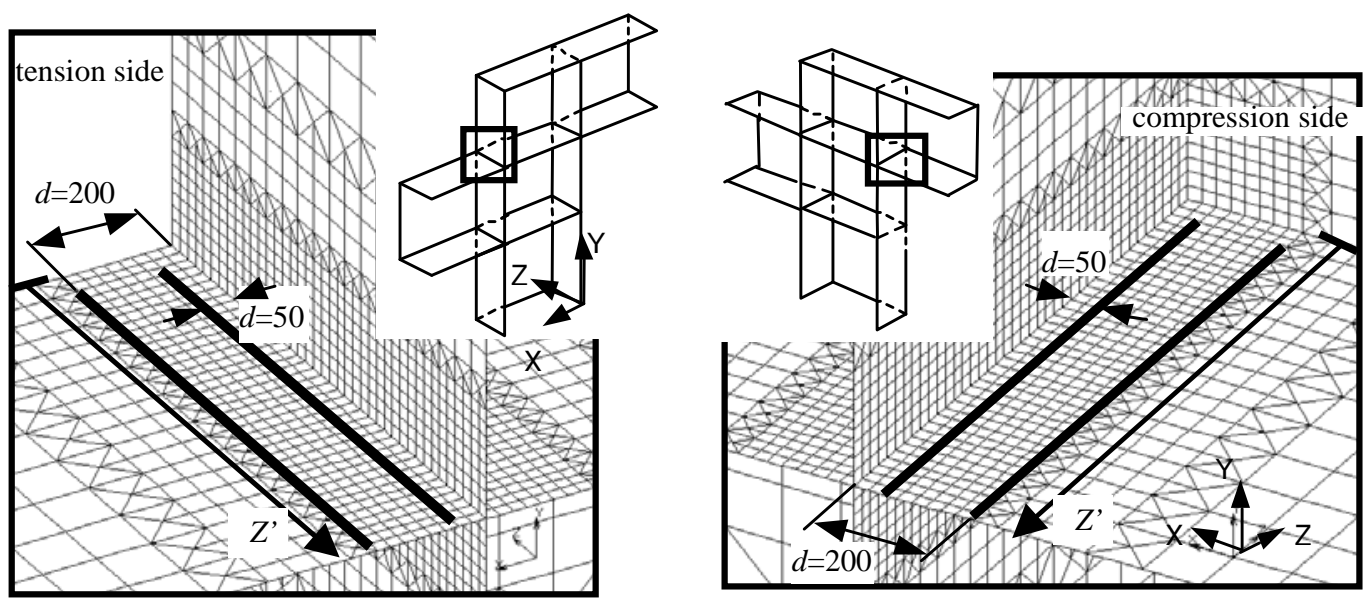

Fig.11. Beam-to column connections

The horizontal axis $Z$ ' in Fig.10 denotes the distance from the opposite edge of the flange (just above the web plate). The core is arranged at the connection of the opposite edge $\left(Z^{\prime}=0\right)$.

In the Fig.10(b), stress along the line at a distance of $50 \mathrm{~mm}$ is decreased showing almost parabolical curve. This is due the shear lag on the flange plate.

On the other hand, the curves in Fig10(a) with $d=200 \mathrm{~mm}$ have the maximum at $Z^{\prime}=135-185 \mathrm{~mm}$ for the case of $r=50,80$ and $100 \mathrm{~mm}$, and at $Z^{\prime}=38 \mathrm{~mm}$ for the model without a core, and at $Z^{\prime}=0$ (just above the web plate), smaller stress is areisen. For example, the model with $r=100$ has its stress of $1.1 \mathrm{MPa}$ at $Z^{\prime}=0$, although the 
maximum stress of this model is $4.2 \mathrm{Mpa}$ and the stress at the center $\left(Z^{\prime}=1000\right)$ is 2.0 $\mathrm{MPa}$. This suggests that the stress near the core is probably disturbed by the core.

\section{Remarks and Conclusion}

In this paper, numerical analysis is made on the thin-walled steel box column which has a hole (core) at the beam-column connection. The results of this study are summarized as follows;

1) When a core is arranged in the zone which is subjected to tension, the core has small influence on the strength of the column irrespective of the radius of the core or the plate thickness.

2) When the core is arranged in the zone which is subjected to compression, the smaller strength of the column is obtained. In this case, larger core radius brings generally smaller strength.

3) The model with thinner plate (i.e. the model in which buckling occurs in earlier stage than yielding), the core has more influence to the strength. In other words, the column is more sensitive to the core radius on the models in which yielding is preceded by buckling.

Generally, the coreing method is used on the zone at which tensile stress is dominant because the method is originally considered with the fatigue strength. These results indicates that the coring method is appropriate method to prevent the developement of the fatigue cracks when the core is arranged in the tension zone.

However, in some cases, the method is adopted on the zone subjected to the alternate stress, that is the zone at which not only the tensile stress but also the compression stress is arisen. When the coring method is applied, buckling strength of the column has not so been took into account. Thus, the results in this paper indicate that the attention should be paid on the buckling strength when the coring method is applied on the zone subjected to the alternate stress.

\section{References}

1. Miki,C., Ichikawa,A., Sakamoto;T., Tanabe,A., Tokida,H And Shimozato,T. : Fatigue performance of beam-to-column connections with box sections in steel bridge frame piers, Jour. JSCE, Vol. 710,pp.361-371,2002.7 (in Japanese)

2. Morikawa,H. Shimozato,T., Miki,C. And Ichikawa,A. : Study on fatigue cracking in steel bridge piers with box section and temporally repairing, Jour. JSCE, Vol. 703,pp.177-183,2002.4 (in Japanese)

3. Tanabe,A., Sasaki,E. and Miki,C. : Seismic performance of steel bridge frame piers with fatigue retrofitting at beam-to-column, Journal of Structural Engineering, JSCE, Vol.51A, pp.1257-1266, 2005.3 (in Japanese) 